\title{
Sik Bilong Ples: an Exploration of Meanings of Illness and Well-Being Amongst the Wosera Abelam of Papua New Guinea
}

\author{
G. KOCZBERSKI AND G.N. CURRY
}

This paper examines indigenous concepts of health and well-being amongst the Wosera Abelam, East Sepik Province, Papua New Guinea. Indigenous conceptual frameworks for understanding human well-being are remarkably resilient despite the use of western medical services and nutritional advice from health clinics. Their resilience is probably attributable to their embeddedness within a wider worldview that emphasises the social context of health and well-being and thus makes them resistant to change. Whilst the Wosera Abelam are open and receptive to modern health services, their response to these services remains considerably influenced by indigenous concepts of health and illness.

In rural Papua New Guinea (PNG) the introduced modern medical system consisting of a network of aid posts, maternal and child health $(\mathrm{MCH})$ clinics $^{1}$ and district hospitals exists alongside indigenous medical practices. Although the latter have not been formally linked with the modern system, there does seem, as Connell (1997) notes, to be a 'syncretism and synthesis' between the two whereby attempts are made to combine treatments from both regimes. Introduced western beliefs and practices have been incorporated into indigenous systems, and illness is usually treated within the modern health care system,

Gina Koczberski and George Curry are geographers in the School of Social Sciences and Asian Languages, Curtin University of Technology, G.P.O. Box U1987, Perth, Western Australia 6845, Australia. though disease aetiology is usually understood in terms of traditional knowledge systems.

In this paper we explore this process of 'syncretism and synthesis' further by drawing on data from the Wosera sub-district, East Sepik Province, PNG to show how indigenous concepts of childhood development and responses to health and illness interact with the introduced modern medical system. We suggest that the beliefs underlying child nurturing practices and concepts of growth and illness are an integral part of a wider indigenous knowledge system that directly influences maternal nurturing behaviour and health care practices, and is thus highly resistant to change. The second part of the paper presents a case study of an illness event of a young girl that highlights the interplay between the modern and indigenous medical systems and how the 
cultural and social contexts of illness influence health care behaviour. We suggest that whilst rural villagers are certainly open and receptive to modern medical treatment, change in health behaviours is less one of displacement of old by new, but more an ongoing process of the blending of modern and indigenous medical systems, with villagers continuing to rely on indigenous knowledge systems to explain health and illness.

Rather than interpreting this resistance to the modern medical system as a hiatus in an inevitable acculturative process usually associated with modernist discourse and modernisation, we draw inspiration from Simon's $(1997 ; 1998)$ recent exploration of a new approach which he terms 'post traditionalism'. We suggest that post traditionalism with its notions of hybridisation and syncretism offers a more useful framework for understanding changing indigenous concepts of health and health care behaviour because it is less deterministic and Eurocentric than functionalist and structuralist interpretations of change. A background to post-traditionalism and its relevance to socio-economic change in developing countries and medical geography is presented below.

\section{Background to post-traditionalism}

Since the late 1980s the relevance to much of the developing world of conventional models of social and economic change located in intellectual modernism (variants of modernisation theory and structuralism) has increasingly been challenged (for example, Nederveen Pieterse [1994], Crush [1995] and Escobar [1995]). These models, which use the western industrialised world as their reference point for change, are premised on Eurocentric assumptions and ideas that are reductionist, universalistic, emphasise western concepts of rationality and view change as a unilinear process. Further, these perspectives view the social, cultural and economic transformation of the developing world as the inevitable outcome of modernisation/globalisation. Recently, however, growing recognition of the indeterminate nature of change in pre-capitalist societies and the resilience of indigenous social, economic and cultural infrastructure and identities (even of indigenous groups within industrial societies), is leading to a reassessment of the nature and accepted inevitability of transformation.

Simon (1998), in an attempt to forge an approach that more clearly recognises the complex and diverse processes of change in developing countries, draws on the ideas of Nabudere (1997) and turns to the notion of posttraditionalism. Whilst post-traditionalism has overlaps and links with post-modernism and post-colonial studies, it differs in that it moves away from the experience of colonialism as the main time-space referent and instead places emphasis on indigenous pre-colonial/premodern values and their durability. By doing so, post-traditionalism recognises that indigenous pre-colonial values, social structures and identities have persisted in many parts of the former colonial world although, to varying degrees, altered and overlain by modernist, colonial and post-colonial experiences, values, and practices. As Simon (1998, 239-240) notes, one of the merits of post-traditionalism is

... the possibility of greater weight being given to indigenous and hybrid pasts, which in turn (re)combine in new hybrid ways ... this means exploring the potential values of the contradictions, fragmentations, mélanges, pastiches and hybrids which are, and have often been for some considerable time, so widespread, 'normal' and even characteristic in ... most countries of the South.

Thus, post-traditionalism as hybridisation and hybridity provides a less Eurocentric and deterministic alternative to the conventional view of such societies as being incompletely modernised or transitional in the sense of being located some way along a continuum towards western modernity. The concept of posttraditionalism enables us to examine and think about change differently by recognising that alternative modernities/outcomes are possible in 
which the pre-modern and pre-colonial are constantly being reworked and interpreted to form hybrid social, economic and cultural identities.

Nabudere's (1997) and Simon's (1998) writing on post-traditionalism resonates with a larger body of mostly anthropological work that has sought to give greater attention and emphasis to the role of indigenous or precolonial elements in shaping contemporary forms of socio-economy and values. For example, in PNG the tenacity of elements of pre-capitalist society and the blending of what could be termed 'traditional' and 'modern' elements is giving rise to hybrid economic and social formations that are neither recognisably purely one nor the other (for example, Gregory [1982], Boyd [1985], Carrier and Carrier [1989], Thomas [1991], Clifford [1997, 147-187], Curry and Koczberski [1998] and Curry [1999]). Such formations can give rise to hybrid sites and spaces so that, for example, urbanisation with the fusion of pre-capitalist and capitalist modes of production can lead to 'cities of peasants' as in parts of Latin America (Roberts, 1978).

To date, these ideas have made little inroad in medical geography, though there have been calls for medical geography to take more account of the social and cultural contexts of health. Recently, ideas from cultural geography have begun to inform research in medical geography with increased attention being paid to the social and cultural contexts of health, including the relationships between experience of place and conceptions of health (for example, Eyles and Donovan [1986], Gesler [1991; 1992] and Kearns and Joseph [1993]), and some medical geographers working in developing countries have called for more analysis of people's beliefs and attitudes to health and illness to understand the acceptance or nonacceptance of particular innovations (Good, 1987; Phillips, 1990; Gesler, 1991).

One under-explored area in the new medical geography is the persistence and durability of indigenous belief systems and the emergence of health care behaviours that draw on introduced and indigenous medical practices and beliefs. Studies in medical anthropology have highlighted the importance of the social and cultural contexts of health (for example, Jenkins et al. [1984], Conton [1985], Lepowsky [1990], Jenkins [1992] and Obrist van Eeuwijk [1992]), and such work has contributed to an improved understanding of indigenous responses and resistance to modern medical services and health education programmes (for example, Jackson and Jackson-Carroll [1994], Landrine and Klonoff [1994], Pollock [1996] and Kirby [1997]). These latter studies suggest that western medical services and health education programmes must adapt to indigenous concepts of health and illness if they are to be better utilised and more effective. For example, Jackson and Jackson-Carroll (1994) argue that nutrition education programmes in Nepal have met with only limited success, because they take a reductionist perspective to health education where attempts to modify 'inappropriate' health behaviours (for example, nutrition and illness response behaviours) are based on notions of 'enlightening' indigenous communities about the 'facts' of health and illness. Health education campaigns are often premised on the view that 'traditional' beliefs are barriers to health which must be overturned and replaced with 'modern' and 'rational' systems of health knowledge. Often such educational campaigns, and western health care generally, underestimate the resilience of indigenous concepts of health and illness, and ignore their embeddedness in broader social and cultural frameworks which give them their social and cultural legitimacy, and hence resilience. For example, in PNG, the indigenous framework sik belong ples (illness of the settlement or society), with illness causation located in social relations, is rarely considered in educational campaigns. These issues are explored towards the end of this paper where we discuss the wider relevance of our micro-study for nutritional education and primary health care programmes in the Wosera. 


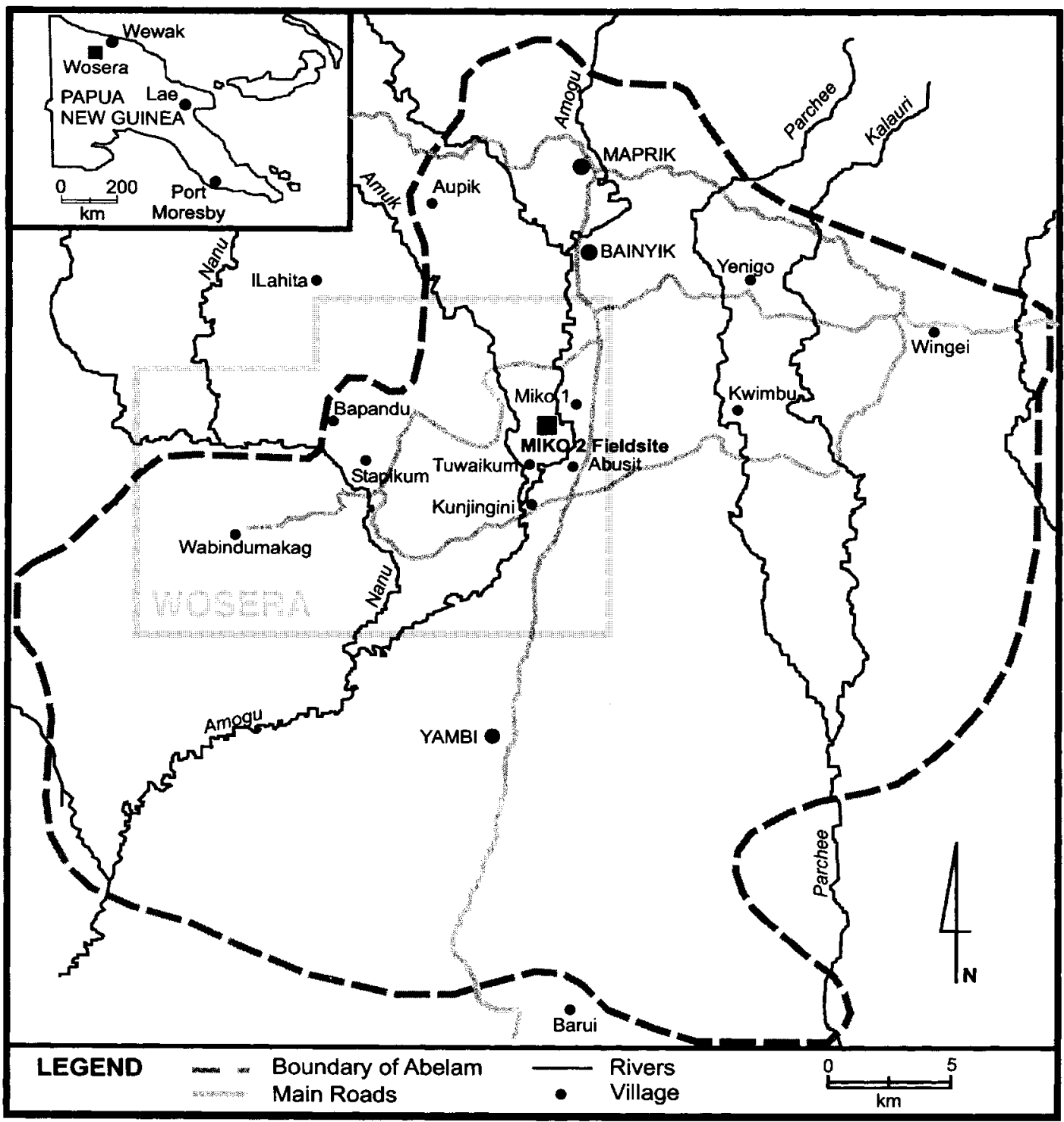

Figure 1 The location of Miko 2 Village in the Wosera sub-district of East Sepik Province, Papua New Guinea.

Study site and methods

The study site of Miko 2 Village is located in the north-east of the Wosera sub-district, East Sepik Province (Figure 1) and in 1996 had a de jure population of 286 , with almost thirty per cent living away. ${ }^{2}$ The Wosera is one of the poorest sub-districts in PNG (Lea et al., 1988), and in 1986, coffee and cocoa incomes were less than one quarter of the rural Papua New Guinean average (Heywood et al., 1986). In 1988-89, per capita income in Miko 2 Village was K24 (K1 = A\$1.47) (Curry, 1992). 
Data are drawn from informal and formal interviews and participant observation over an 18 month period in 1988-89 in the Wosera village of Miko 2. A return three-week visit in January 1996 provided additional data and observations. Whilst data are drawn from informal interviews and observations of the entire village community, most of the qualitative data in this paper are derived from five village families with whom we lived in close proximity and were thus in a position to observe and interview at least weekly. These five families all had young children, the youngest in each family ranging from under one month to 36 months of age. Other families were interviewed and observed less regularly. This extra information supplemented that from the five primary households.

The research relied mainly on ethnographic techniques which involved a relatively long period of immersion in the village socioeconomy, and participating in or observing the everyday activities of village life including occasional community and ceremonial events. Over 18 months we came to know most villagers. A prolonged fieldwork period and engagement with village society facilitated our acceptance by villagers, which enabled us to explore the social, economic and cultural relationships of village society to gain insights into how people understood their world, including the impacts of external forces that were influencing their everyday lives. A great deal of information was collected through informal discussions and observations when visiting people in their gardens or hamlets, and when relaxing in the evenings with village residents and visitors. Where possible, information collected in this way was crosschecked with other people (usually with someone from a different subclan), which often resulted in additional information or clarification of some misunderstanding on our part.

The value of ethnographic methods to geography has recently been emphasised by geographers since the so-called 'cultural turn' in geography (see Anderson and Gale [1992],
Brown [1995] and Philip [1998]). Also, Gesler (1991, 182), in an attempt to map a new approach for medical geography that places greater importance on the role of place in illness, notes that future research should be based on 'thick description' involving living and immersing oneself in the study area. Whilst the value of ethnographic techniques is now becoming recognised more widely by human geographers, it must be acknowledged that these techniques have been used for a considerable time by geographers working in developing countries. For example, ethnographic techniques involving lengthy fieldwork periods and a mix of qualitative and quantitative approaches have been characteristic of the work of many geographers working in PNG since the early sixties (for example, Lea [1964], Brookfield [1973], Howlett [1973], Allen [1976], Crittenden [1982] and Tyson [1987]).

\section{Subsistence setting}

Wosera subsistence production is strongly seasonal and characterised by a bush fallow system of gardening alternating with sago processing. Yams (Dioscorea esculenta) are the primary food crop and are cultivated in gardens and interplanted with taro (Colocasia esculenta and Xanthosoma sagittifolium), and a range of supplementary crops. Sago is the most important non-garden food and is the primary staple (supplemented with bananas) from January to June when yams are in short supply. Bananas (Musa spp.), coconuts and tulip (Gnetum gnemon), small game animals and insects are also important supplementary foods at different times of the year.

Yams are also an important element of Wosera ceremonial life, whereby long elaborately decorated yams (Dioscorea alata) are exchanged between ritual exchange partners (Kaberry, 1941; Forge, 1971; 1990). Successful yam growth is symbolically associated with male strength and prestige and has important implications for male economic and political ambitions and, to a lesser extent, family wellbeing. For this reason growers invest much 
effort in growing large tubers. Various rituals are performed, and behavioural and food taboos are observed during the growing season to promote successful yam growth.

\section{Nutritional setting}

In the early 1960s the Wosera people were reported to be severely malnourished (Bailey, 1963; Schofield, 1963) as a result of food shortages, and low protein and calorie intakes. The infant mortality rate for the area was 500600 per 1000 live births (Peters, 1960). More recent investigations in the sub-district continue to report a high infant mortality rate (140 per $1000)$, poor health, and high malnutrition rates especially amongst mothers and young children (Ross, 1984; Heywood et al., 1986; 1988; Garner, 1989; Shack et al., 1990). The National Nutritional Survey of 1982-83 reported that the nutritional status of Wosera children was amongst the worst in PNG (see also Gillett [1990]). Sixty three per cent of children under five years of age were classified as malnourished (that is, below 80 per cent of weight-for-age of the Harvard Standard).

Variables implicated in the aetiology of childhood malnutrition in the Wosera include low food intakes, poor maternal nutrition, heavy workloads of women, low birth weights, late introduction of solid foods, lack of nutritionally appropriate weaning foods, frequent illness, overpopulation and poverty (Ross, 1984; Heywood et al., 1986). Several studies in PNG have associated the late introduction of solid foods with growth retardation (Malcolm, 1970; Cogill and Clarke, 1984; Jenkins et al., 1984). These studies suggest that after four to six months of age, breastmilk as a sole source of nutrients does not meet the protein and energy demands for rapid infant growth. In the Wosera, the eruption of teeth at around seven or eight months of age is seen as an indication that supplementary feeding should commence. This delay in starting supplementary feeding may in part be responsible for the growth faltering that begins to occur in children at around six months of age. It is also possible that Wosera children are disadvantaged nutritionally by infrequent supplementary feeding and a feeding regime based on weaning foods deficient in energy and protein (Ross, 1984; Heywood et al., 1986). However, more detailed studies are required to investigate these issues.

Wosera $\mathrm{MCH}$ clinics stress to mothers that supplementary feeding of nutritious foods such as mashed pawpaw and/or banana should commence at four months of age. In 1988-89, $\mathrm{MCH}$ clinics were held in Miko every two to three months and most mothers attended regularly for medical treatment and immunisation of their children, and/or to have their children's growth recorded. During clinics, mothers were often reminded to introduce solids early, particularly those whose children were experiencing growth faltering. Yet, very few Miko mothers followed this advice. Miko mothers were familiar with $\mathrm{MCH}$ nutritional messages and nearly all insisted during initial interviews that they commenced supplementary feeding at four months. Repeated observations, however, revealed that whilst they had learned nutritional messages, they were not following through with this information, and, typically, supplementary feeding began at six or seven months of age. Also, pawpaw, a supplementary food recommended by MCH staff, is not considered 'real' food and is often only eaten in gardens to quench thirst or to temporarily fill the stomach until some substantial food can be consumed (for example, cooked yams or bananas and soup). Pawpaws are cultivated mainly for pig consumption and ripe bananas are commonly produced for sale at local markets. Moreover, pawpaw and banana are usually given to infants so irregularly and in such small quantities that their contribution to diets is likely to be negligible. Thus whilst mothers are aware of the nutritional advice provided by $\mathrm{MCH}$ clinic nurses, very few act on this advice.

Apart from attendance at $\mathrm{MCH}$ clinics, mothers regularly sought medical treatment for their children at the nearby health clinic or Maprik District Hospital. Information from 46 
clinic books revealed a mean of two trips per month per child to a health clinic or hospital in the first six months of life, with a slight decrease to 1.8 trips per month for the second six months of life (Koczberski, 1989). Because illness is often untreated these figures probably underestimate grossly the number of sick days experienced by Miko children in the first year of life, but they reveal that mothers are accustomed to and routinely use modern health care services.

\section{Cultural setting}

Subsistence production and the general wellbeing of people are intricately entwined with Abelam cosmology. The most important Abelam spirits are those associated with patrilineal ancestors, collectively called gwaleaba. The support of the gwaleaba is necessary for successful yam growth (both ceremonial and main food varieties), and is fundamental to the well-being of individuals and groups through their influence on food production, pig husbandry, health and female reproduction. Throughout the year, appeals and propitious offerings of food are made to the gwaleaba to harness their support in the cultivation of yams (usually at planting and harvesting), and to heighten their watchfulness over the gardens, sago groves and well-being of living descendants (see below). Moreover, daily exchanges of food, labour and wealth between patrilineage and subclan members reinforce kinship ties and demonstrate to the gwaleaba kin-group solidarity and harmony amongst living descendants. Disharmony between living clan members may lead the gwaleaba to withdraw their support, thereby allowing misfortune such as crop failure or illness to befall their living descendants. Therefore, intra-lineage and subclan rifts are often resolved quickly by members coming together to share a specially prepared meal to appease their gwaleaba by demonstrating renewed lineage or subclan solidarity. A very close link is thus perceived to exist between the spirit world and that of the living as ancestral spirits are seen to underpin all aspects of the daily lives of people.
Closely associated with ancestral spirits and individual well-being is the role played by mother's brother (MB). MB wields considerable influence over the well-being and actions of his sister's children (Curry, 1997). The relationship between MB and sister's son/daughter is culturally significant in many parts of Papua New Guinea. In the Wosera, this relationship is grounded in a belief system encompassing the role of a woman's natal subclan fertility spirit in conception (the 'life force'), and the arrangement of supernatural and spiritual forces that allow MB influence over his sisters' children. Because sisters' children were conceived by MB's clan fertility spirit (wale) and their flesh and blood fashioned from MB's clan, then MB can influence their health, wealth and general well-being as well as the reproductive capacity of sister's daughter by utilising the power of his own ancestral complex. MB can call on his ancestral spirits to curse his sisters' children should he be angered by their actions, or feel that they are not fulfilling their customary obligations to him.

Sorcery is pervasive and most feared and is perceived to be the cause of major lifethreatening events and most deaths. Accusations of sorcery usually arise from disputes over land, sago, pigs or personal and group jealousies. To perform sorcery, the sorcerer must have in his possession an item that has been in close physical contact with the intended victim such as food scraps, cigarette butts, bodily excretions, hair or bits of clothing. Because of the care with which most villagers dispose of such items, it is believed such material is collected opportunistically. This means that if a member of a kin group is involved in a dispute, anyone from his/her group is a potential target for sorcery whether or not he/she is an active participant in the dispute. Whilst any member of the group is perceived to be vulnerable, children, or someone ill for another reason, may be targeted because they are thought to be more vulnerable to the effects of sorcery. Infants, not yet walking and in the constant supervision of their mothers, provide less 
opportunity for the collection of personal items, so older, independently mobile children are believed more likely to be targeted.

Thus, Wosera cultural and social life is dominated by omnipresent supernatural and spiritual forces which structure daily routines and are invoked to explain everyday phenomena and the well-being or otherwise of people. Ancestral spirits, mother's brother, witchcraft and magic, including sorcery, are all important elements of everyday life believed to influence the behaviour, well-being and health of individuals and groups. Minor mishaps such as inconsequential falls, misplacing an item, momentary dizziness, or unexplained noises and events can all find some supernatural explanation. These same supernatural and magical forces are also perceived to influence the health and growth of children. Villagers often view illness and delayed child development as a consequence of the presence of these harmful elements in the environment. The significance of these beliefs for child nurturing and feeding practices and concepts of child growth is discussed below.

\section{Concepts of child growth and well-being}

This section addresses the question of why traditional child nurturing practices are resilient and persist despite sustained programmes of nutritional education, amongst people who regularly seek and use modern medicine. Part of the explanation may lie in the beliefs surrounding child growth and well-being. As mentioned earlier, most facets of Wosera life are bound up in a worldview based on the existence of, and interaction with, supernatural elements over which people have only limited influence. These same supernatural forces are also perceived to act on the growth and well-being of infants and children.

Mothers largely assess child growth by progress in motor development and tooth eruption, and to a lesser extent by the weight or height/length of a child. A mother often recognises poor growth by what she perceives as unusually slow progress in motor development and by reference to other children in the same age cohort. Since there are several village births each year, there is always a yardstick available to mothers with which to compare their own children's growth. Obrist van Eeuwijk (1992) reports a similar frame of reference for monitoring child growth amongst the nearby Kwanga. If, for example, a child is lagging behind others in its own age group, then a Miko mother and/or close kin may begin discussing its slow development. However, rarely is delayed development associated with insufficient food intake or recognised solely as a food problem. Rather, poor growth and development are believed to result from the same supernatural and magical forces that influence gardening, fertility, death and everyday phenomena. This is illustrated by the numerous parallels between yam and child growth and development. Many of the food taboos and behavioural codes surrounding childbirth and growth, and the rationale attached to them, are synonymous with those associated with the cultivation of yams. Wild game is not consumed by both husband and wife in the first four to six weeks following childbirth, or by males cultivating ceremonial yams. Failure to adhere to this taboo will impede the subsequent growth and wellbeing of the infant or adversely affect yam growth.

Sexual intercourse by a lactating mother is also believed to be damaging to her infant's growth. Sexual activity is said to contaminate breastmilk resulting in the poor growth of the infant. Some say that one can recognise a child who has been given 'contaminated' breastmilk as they often have a swollen belly, large round eyes, small head, and thin arms and legs symptoms of kwashiorkor (Edwards, 1989). Ideally, therefore, the period of abstinence should remain until the child is fully weaned. Similarly, to promote yam growth sexual activity is proscribed. Sexual activity is believed to impede yam growth by restricting the 'mother' yam's capacity to provide 'nourishment' to her 'children', leading to fewer 
and smaller yams. Thus, a parallel relationship is seen between sexual activity and child growth, and sexual activity and yam growth, in as much as the nourishment given by the seed yam to its 'offspring' is impaired. Whilst villagers report that sexual abstinence during the yam growing season is not as strongly followed as before, it is still commonly cited as the most likely cause of the poor growth of yams and children. In one instance, where a child was developing slowly, several women diagnosed the problem as relating to the parents' breaching the sex taboo. The parents, on the other hand, attributed their son's slow development to scabies which had afflicted the child since shortly after birth.

The role of the gwaleaba and other supernatural forces in yam production have parallels in child growth. Just as the yam cultivator makes meal offerings to the gwaleaba to enhance yam growth, meal offerings are also made to the same spirits to promote the wellbeing and growth of sick or poorly developing children. Moreover, for the successful growth of children and yams, harmonious relations are necessary between living clan members as well as with the gwaleaba. Unresolved conflicts between lineage members can result in either illness in children and/or poor growth of yams. On one occasion we heard a woman in a house nearby yelling to kin in an adjoining hamlet. The woman later revealed that her sick infant was showing no sign of improvement after she had made two two-hour walks to the health clinic for medicine for her child. She blamed a current conflict between two members of her lineage for her child's continued illness, and demanded they resolve the dispute. She told them that she was wasting her time making lengthy trips to the clinic and that they should consider the well-being of other lineage members by resolving the dispute immediately. In another example, at a brideprice settlement, the groom's paternal uncle stressed repeatedly the need for members of the bride's natal lineage to state publicly their satisfaction with the amount and distribution of the brideprice.
He feared that if someone harboured a grievance over the amount or disbursement of the brideprice, the children of the marriage would not thrive. In both cases harmonious relations between lineage members were considered crucial to the well-being of children.

Other means to promote the growth of yams also find their parallel in those for children. Whilst the form and content of these activities varies between and across families and yam growers, each is characterised by pleas to the gwaleaba for their support and mostly involves food offerings. For example, just before planting or around the time when the yam vines flower, gifts, such as a rope of betel nut (Areca catechu) or coconut will be placed in the garden for the gwaleaba to consume. Likewise a mother concerned about the health of her child may make the gwaleaba a presentation of cooked food. In many cases these 'gifts' are made at a small gathering of lineage members sharing food together, especially after a rift between lineage members. On other occasions, if a child is not achieving the recognised 'normal' growth pattern of motor development, then a more elaborate ritual may be performed, whereby the mother's brother (MB) may spray saliva on his hands and then slap the buttocks and legs of the child. In this case MB asks his gwaleaba for their support in helping to strengthen the child's legs. We recorded two instances of this ritual during fieldwork in 1990. The first child was 18 months old and could not stand without support, and the second was 27 months and unable to walk.

The above discussion has highlighted the very close parallels between what is perceived to influence yam and child growth, which suggests that people do not necessarily view the influences on child growth as discrete and separate from other aspects of life. A final point to consider is the perceived relationship between illness and poor child growth. Miko children in their first three years of life are frequently ill. Yet, the relationship between poor nutrition and illness is not strongly recognised by villagers. It is only prolonged illness, caused by ancestral 
and water spirits, witches, sorcery or mother's brother, that is seen as a causal factor of slow growth, not the nutritional stress resulting from an inadequate diet. Similarly, amongst the neighbouring Kwanga, Obrist van Eeuwijk (1992) reports growth failure in children is not necessarily attributed to poor diet, but to illness caused by spirits, sorcery or breaching a taboo.

Mother's brother and witches are suspected in many cases of childhood illness. MB may be implicated if it is thought that a family dispute or failure to fulfil obligations to MB has caused him to harm the child. Parents are usually careful to avoid this contingency by quickly resolving family disputes and ensuring that gifts of wealth, food and/or labour are adequate. Witches are perceived to be the most troublesome, and are cited as the main cause of death in the first two years of life. They are also believed responsible for growth retardation through their ability to cause prolonged illness. For example, the parents of a boy who was not walking independently at the age of 36 months believed the reason for the boy's slow development was an earlier attack on the child by a witch. The attack occurred shortly after a heated dispute over land in which their lineage was directly involved. At the time, the boy was hospitalised and, whilst he survived, the parents claimed that the assault resulted in the child's subsequent poor development. There are several suspected witches in the area, and on a visit in 1989 we were told of a recent fight that had erupted in the village after the identification of two witches who were believed to be responsible for the death of a young boy. One man in the fight partially lost the use of his right hand, whilst others carried the scars of spear wounds.

Mothers see sorcery as less of a threat than witchcraft to the health of children under two years of age. For the first two years of life a child spends most of its time either strapped to its mother's side or in close contact with her so that there is little opportunity for the collection of items that could be used to harm the infant through sorcery. However, the effects of sorcery can be transmitted to an infant via breastmilk. During fieldwork the death of a six month old infant a month after her mother's death was attributed to the mother breastfeeding her infant whilst suffering from a sorcery-induced illness. When the mother died, it was considered inevitable that the infant would also die. Women who were breastfeeding the infant prior to the mother's death gradually distanced themselves and much of the responsibility for the infant's welfare fell to its young female siblings. The infant's subsequent rapid wasting and bouts of illness were interpreted as direct effects of the sorcery, and therefore the sick infant was not encouraged to eat and medical care was abandoned. Women reported a similar case in the village several years earlier.

According to the Wosera worldview a successful passage through childhood is achieved by: adhering to the food taboos and behavioural codes following childbirth and during the weaning period; striving to maintain lineage and subclan cohesiveness through promoting harmony and minimising conflict within the group; and avoiding the harmful effects of other supernatural forces present in the child's environment. Whilst most mothers recognise that food is necessary for growth, the strength of the relationship is not perceived to be great. For a mother, food alone will not ensure successful child growth. Just as a yam grower is unlikely to attribute a poor harvest to soil quality or weather conditions alone, a mother is unlikely to attribute her child's poor development to inadequate food intake. Failure to achieve successful yam or child growth is much more likely to be attributed to omnipresent supernatural elements.

Because food is seen as playing only a minor role in the health and nutrition of children, it may explain why little time or effort is expended on preparing special weaning foods or using food to redress illness and growth faltering. Instead, a mother's efforts are directed to quelling the more immediate and 'real' dangers posed by the complex of supernatural forces, as evidenced by the high rates of illness 
amongst children. Also, such beliefs may partly explain why modern medical advice that stresses the importance of food for child growth has not been fully accepted by mothers, and why child feeding patterns are proving so resilient to change. Whilst there has been a shift in the way child health is managed by mothers (for example, most children are now immunised), there appears to have been little cultural change in what people perceive to be the underlying factors affecting individual well-being.

\section{Social context of illness}

To this point, this paper has largely explored the cultural framework within which child nurturing occurs, and suggests that mothers' responses to growth faltering and illness are influenced by cultural beliefs and Wosera cosmology. What remains to be explained is how a family's response to illness is shaped by the specific social context in which an illness event occurs. The question then becomes, in what contexts do these beliefs become especially important and relevant to the nutritional status of the child? Such a question warrants further research, especially in relation to issues of place and identity, and we attempt briefly to address several aspects here. We argue that whilst there is a shared system of meanings and beliefs, the type and form of behavioural response (and hence child nutrition) is influenced by the specific social context of an illness. That is, there may be specific situations where the cultural beliefs surrounding child well-being become particularly important in determining a mother's nurturing behaviour, and in turn the health of her child.

Villagers distinguish between sik bilong ples and sik nating (illness without cause). The former category refers to illnesses that are believed to be located in social relations broadly defined and encompassing the world of the living (kin and non-kin), ancestor and other spirits. Sik nating refers to other illnesses where there is no perceived social or spiritual cause and which are readily treated by traditional herbal or modern medicines. This distinction is wide- spread in Melanesia though there appears to be considerable variation between societies in the proportions of illnesses designated as each type and little uniformity in how specific illnesses are defined in terms of each category (Schwartz, 1969; Lewis, 1975; Hamnett and Connell, 1981; Frankel, 1986). Some researchers have reported that whilst modern medicine is believed to be able to alleviate the symptoms of sik bilong ples, indigenous remedies are thought to be required for the elimination of underlying causes (Schwartz, 1969, 208; Hamnett and Connell, 1981, 497; Frankel, 1986, 181; Lipuma, 1989, 301; Roscoe, 1989, 211).

Illness diagnosis can shift between these two categories depending on many factors including illness duration and progress, the efficacy of various treatments and the social context of an illness event. For example, if a child's illness or poor growth is contemporaneous with an intralineage conflict, then this conflict is likely to be seen as the source of the child's illness, and responses will be immediately directed to resolving the conflict and placating the gwaleaba. However, if a sick child is not responding well to modern medicine and no contemporary problem can be identified as the cause of the child's illness, the search for an explanation can, and often does, lead to a reanalysis of past events to find an appropriate explanation. Therefore, the shared system of beliefs and meanings constituting the Wosera worldview assume added significance in particular social contexts, and invariably these are entwined with notions of place and identity. If the cause is identified as supernatural in origin, then the response strategy must also be in this realm. The interplay between the cultural environment and the social context of illness was illustrated in the following case study of the illness of an 11 year old girl, Mira, ${ }^{3}$ when we made a return visit to the village in 1996.

We first heard of Mira's illness on a Thursday afternoon. She had been suffering from stomach pains for the previous two days and was not eating or sleeping well, but still drinking fluids. Her grandparents told us that the pains were like 
sharp cramps that came and went. The rest of her body felt fine and she was not suffering from diarrhoea or constipation. They were unsure about the type of illness, as it was not like other stomach upsets that usually occur alongside other symptoms such as diarrhoea or an aching body. On Friday morning Mira's mother took her daughter to the health clinic where she was prescribed a series of antibiotics to be administered at the health clinic over the next five days. That night the stomach cramps worsened and Mira's mother, who had just joined a new evangelical church, asked the pastor to come and pray for her child. The prayers were said to have relieved the pain slightly, but by the morning the child was still feeling poorly.

On the Saturday morning Mira's maternal grandmother carried her to the health clinic for the second injection, and on the way, she met a distant male relative of her husband, who told her that the child's illness was probably caused by sorcery and to come to him if they needed advice. On the Sunday morning the grandmother again carried Mira to the health clinic for her third injection. However, concerns over the child's continuing illness were building as there was no evidence that the medication was working, and Mira continued to show little interest in food and remained sombre. That night the stomach pains were severe, and at around 2:00 a.m., the parents carried Mira to the house of one of her maternal uncles in an adjoining village. The uncle prayed for Mira and his wife cooked some sago for their niece. The act of sharing food with her MB's lineage demonstrated to her MB's gwaleaba that there was no discord between Mira and her MB that may have caused them to harm her. Also, by sharing food with his sister's daughter, the MB made a public statement that he was not the cause of the child's illness. That night the family stayed at the uncle's house and Mira's pains subsided considerably and we were told she slept peacefully. In the morning, following the uncle's advice, the mother took Mira to the district hospital where they remained for the night. That evening several members of Mira's lineage gathered in the hamlet of another MB (the hamlet in which we were residing) to discuss potential causes of Mira's illness. The blame was put on an elderly man in the village, Nakravi, and evidence was cited to confirm him as the likely sorcerer. As the night progressed contempt for Nakravi reached a volatile level and there was much heated discussion and debate about the type of retaliation that would be inflicted on Nakravi and his lineage if Mira died. After most people had left the hamlet, Mira's father and grandfather explained to us why they believed Nakravi was the cause of Mira's illness. They said that Nakravi's status as a sorcerer had been confirmed as he was seen associating with known sorcerers from a neighbouring village, and in the previous year Mira's maternal uncle, suspecting Nakravi was a sorcerer, broke into Nakravi's house and found items that could be used in sorcery. Also, we were told that a few nights earlier, Mira dreamt Nakravi had taken a piece of her clothing and intended to use this to harm her through sorcery. Because dreams are considered to reflect reality, this was further evidence implicating Nakravi. We were informed that three or four years earlier, whilst Mira washed in the river, her skirt was stolen from where she left it on the river bank. Mira's relatives came to believe that Nakravi acquired the skirt, perhaps through an intermediary, and used it to make several parcels of sorcery, each to harm Mira. This process of reasoning had pieced together the cause of Mira's illness.

On the Tuesday morning, Mira's father, maternal grandfather and maternal uncle collected her from the district hospital. They said that Mira had not experienced stomach pains whilst in hospital, and hospital staff told them to take her home because there were no medical signs of illness. When hospital staff report that they cannot diagnose the illness, villagers generally take this to mean that the illness is sik bilong ples, meaning that the illness has its roots in the village through supernatural means, and overcoming the illness is thus a 
village affair. So Mira arrived home, her family both pleased that her stomach pains had subsided, but concerned the hospital was unable to diagnose any specific problem.

At around midnight that night we were awoken by wailing and much commotion just outside the house in which we were sleeping. Mira was lying in a foetal position on the ground with her parents, maternal uncle and other lineage members gathered around her. Mira's parents said that the cause of the illness was definitely village-based as every time the child left the village (i.e., to visit her maternal uncle in the adjoining village and the hospital) the pains subsided, only to reappear when she arrived home. In an effort to quell the pain, Mira's parents took her to the acting pastor for faith healing. He said some prayers and gave them a half-filled bottle of 'holy water' to keep close to their daughter. Later they returned to her maternal uncle's hamlet to seek his help. Her uncle tied a length of bush rope around her stomach as a way of 'blocking' the sorcery from entering her stomach, whilst the bottle of holy water remained by her side. Her wailing, however, continued and talk again shifted to the cause of the sorcery. In the early hours of the morning, some of Mira's lineage set off to a nearby village to obtain some traditional medicine made from bush plants ('cow-wat') to counteract the effects of the sorcery.

The following day Mira's mother informed us that she was not going to complete the child's course of injections because Mira's illness was sorcery-induced. At this late stage only 'traditional' methods could overcome the illness, and the effort to procure some 'cowwat' was a move in this direction. By that afternoon the possible benefits of the trip were becoming apparent as Mira's pains had eased considerably and much of the anxiety of the previous night had dissipated. Two days later when we left the village, Mira was recovering from her illness. Although still weak, Mira's pains had disappeared and there was an optimism amongst her family (though tempered with caution from previous experience of sorcery-induced illnesses) that they had successfully beaten the sorcery.

The above episode illustrates the complexities surrounding illness and treatment regimes. In this particular case certain specific conditions were present to lead to the 'rational' identification of the cause of the illness, consistent with a Wosera worldview. Because the illness was atypical and not associated with the 'usual' symptoms accompanying stomach cramps, suspicions in the immediate family were aroused. Whilst these suspicions were confined to the family, at least initially, modern medical treatment was obtained from a health clinic with a prescribed course of antibiotics over a fiveday period. At the same time attempts were made to eliminate $\mathrm{MB}$ as the cause of the illness. Sharing food with his sister's daughter showed publicly that he himself had no malicious intents, and demonstrated to his ancestral spirits (and thereby gaining their support) that he had no ill-feeling towards her or her family. Because no improvements in the child's condition were observed in the first few days of medical treatment, initial suspicions of sorcery were heightened and subsequently reinforced by the suggestion of someone from outside the immediate family that sorcery may be the cause of the illness. This marked a turning point in the management of the illness. There were growing doubts concerning the efficacy of modern medicine, and the experience at the district hospital reinforced the view that modern medicine was not 'strong' enough to tackle an illness with supernatural origins. Efforts to counteract the illness included prayer as well as more 'traditional' supernatural means. Once the illness was 'confirmed' as sik bilong ples and therefore the cause and cure were to be located in the constellation of social relations that constitute the Wosera lifeworld, there was a concerted effort to identify the source of the illness which included a reassessment of past events to uncover likely causes and reasons. At this point western medicine was abandoned, and instead efforts were directed at the more important task of 
quelling the sorcery. Moreover, throughout the illness the child was not encouraged to eat, and the only importance food played was as a means of displaying lineage cohesiveness to the gwaleaba.

The social context of indigenous health behaviour has been documented in other recent studies (for example, Jackson and JacksonCarroll [1994], Pollock [1996] and Kirby [1997]). Jackson and Jackson-Carroll (1994) drawing on Giddens' notion of structuration argue that routine health behaviour with regard to diarrhoeal illness amongst the Tamang of central Nepal is grounded in specific social relations that help structure many aspects of Tamang daily life. The social institutions and cultural values of village life are drawn upon and reproduced by routine health behaviours which thus sustain historical and cultural continuity (Jackson and Jackson-Carroll, 1994, 999). Illness, like other facets of Tamang life, is often a socially experienced event whereby the cause (as well as the response) may be located in social relations. Similarly, amongst the Wosera, the social context of illness can be central to identifying the cause and determining the response to illness. If an 'obvious' social cause such as an intra-lineage conflict coincides with an illness, then the illness becomes a socially experienced event and the lineage pursues strategies to resolve the conflict; if a sick person is slow to, or fails to, respond to western biomedical treatment, then the illness becomes a socially experienced event as current and past social contexts are examined for likely causes and potential solutions.

Whilst unusual symptoms or combinations of symptoms are more likely to be diagnosed as sik bilong ples than sik nating, in the early stages of illness, diagnosis may switch several times between the two categories with close relatives sometimes holding opposing views on the diagnosis. This ambivalence is often reflected in a syncretic regime of treatment that an ill person may experience over a short period, so that, for example, modern medical treatment may be sought at the same time as supernatural remedies, both indigenous and Christian, are attempted. Thus, illness treatment regimes are made up of introduced and indigenous elements which may appear logically inconsistent to the outsider (for example, holy water, modern medicine and supernatural strategies to counter sorcery). However, because someone uses modern medicine does not mean that they subscribe to a scientific understanding of health and illness. As Frankel and Lewis (1989, 33) note '[y]ou do not have to accept a particular body of knowledge or beliefs to swallow a tablet or inject someone with penicillin. All you need is the equipment.' Thus, this hybridised regime which is neither traditional nor modern can be viewed as post-traditional in the sense that strategies of illness management criss-cross both frameworks drawing elements from each depending on the nature and type of illness and its social and cultural context. Moreover, the regime does not suggest a loss of the 'traditional' but rather is an example of how the introduced and the indigenous are drawn upon and reworked by villagers to create alternative modernities.

\section{Conclusion}

Wosera concepts of child growth and illness, subsistence production, hunting, social relations, cosmology and the general well-being of individuals and groups form an overarching cultural belief system that together constitutes the Wosera worldview and structures aspects of everyday life. The robustness of indigenous health beliefs results from their intermeshing and interconnectedness within a wider holistic worldview that, overall, gives the complete system of beliefs and concepts of the world its resilience. This does not suggest that cultural beliefs present insurmountable barriers to health and nutritional education, nor that indigenous beliefs and socio-cultural forms are static and have persisted unchanged from the pre-colonial period. Rather, as with other introductions (for example, the cash economy and Christianity), Miko villagers are incorporating aspects of modern health care into their indigenously 
defined frameworks of health and illness, and in the process creating hybrid forms.

The syncretism of the two systems suggests that nutritional education programmes in the Wosera, and possibly elsewhere in PNG, would benefit from sensitively accommodating indigenous concepts of health and illness and recognising that the resilience of such concepts results from their embeddedness within a wider cultural belief system. Yet, a western medical understanding of poor child health remains the basis of programmes of nutritional advice and education in the Wosera. Such an understanding has validity from a scientific viewpoint but does not form a valid basis for educational campaigns directed at populations that do not share this epistemological perspective.

Moreover, because concepts of health and illness are grounded in a particular worldview and cultural and social complex, then a reductionist western biomedical approach which seeks to modify nurturing and illness response behaviour on the premise of a distinct and separate set of beliefs pertaining to health and well-being is likely to be of limited success. It may be more appropriate to develop approaches sensitive to the linkages between indigenous health behaviour and their social and cultural contexts, and to the interplay between the different medical systems. As Garner ([1989, 136] and see also Kirby [1997, 229]) argues in his study of maternal and neonatal health in the Wosera, '[a]s health workers, many of us try to impose on our patients what we feel is right for them. Perhaps we should learn to listen a little more.' Learning more about indigenous concepts of health and illness, particularly the indigenous concept of sik bilong ples, also provides an opening point for acknowledging the resilience and dynamism of indigenous health care practices and beliefs.

Writing thirty years ago of the persistence of indigenous health beliefs and practices in Manus Province, PNG, Schwartz $(1969,208)$ stated:

I have the impression ... that there is a nativistic loyalty to native diseases - their sick belong ground which lie beyond the sphere of European knowledge and power. Here is an area in which an older world view adapts and persists for those who have known the past to which it belonged ... European medicine has a long period of competition ahead for primacy in the hierarchy of resort.

Schwartz's statement appears as valid today as it did three decades ago. It may be time to consider additional approaches to the conventional one of educating villagers about the biomedical 'facts' of health and illness. Perhaps a better strategy would be to improve medical outcomes so that modern medicine becomes the treatment of first resort as an increasing proportion of illnesses and illness types become designated as sik nating. Despite declining access to modern medical services, particularly in rural areas (Connell, 1997, 283), there is scope for improved medical outcomes using existing resources. One of the most persistent and widespread problems with modern medical services in PNG is the low rate of compliance with treatment regimes. For example, a five-day course of antibiotics is typically followed for only two or three days (Jenkins, 1992, 395). Yet, compliance rates for regimes of indigenous treatment are generally high, despite their often considerable expense relative to modern medicine. With sorcery, for example, victims are often aware that several sorcery 'bundles' are making them ill. Treatment then becomes one of 'neutralising' each bundle, a treatment regime that villagers acknowledge is sometimes prolonged, and frequently involving a series of discrete steps. Similarly, a treatment regime of antibiotics could be explained as a series of steps to 'neutralise' the illness with full recovery not expected until the final injection is delivered. By drawing parallels with indigenous treatment regimes compliance rates for modern medicine could be raised, which would be likely to enhance medical outcomes. This of course raises ethical questions, but it may disabuse villagers of the view that modern medicine can 
effect instantaneous cures only in cases of sik nating, whilst, at best, only ameliorating symptoms in cases of sik bilong ples.

How then should medical geographers be viewing change in health beliefs and behaviours? Is it naive to expect 'Third World' rural societies or even urban societies where acculturative pressures are arguably greater, to switch to a modern scientific understanding of illness and well-being? We would argue that such views, though well intended, are unrealistic. Indeed, as mentioned earlier, the accepted inevitability of transformation is increasingly being questioned with the growing realisation that 'traditional' societies are remarkably resilient and a variety of economic and social forms are emerging that contain both 'traditional' and 'modern' elements. This recognition is challenging the dominant models of change and fuelling a search for alternative explanations that are sensitive to local contexts and which pay greater attention to the indigenous social and cultural contexts of change.

Post-traditionalism with its notions of hybridity recognises alternative possibilities in which diverse socio-economic and cultural formations are the expected, the norm. This perspective does not presuppose the progressive displacement of the pre-modern and the indigenous with the modern and the introduced, but instead recognises a more complex and dynamic situation in which the modern and premodern, Christian and pre-Christian, the market and non-market, are becoming articulated in ways that are constantly shifting to create a range of alternative modernities. We suggest, therefore, that a post-traditional approach to investigating health care behaviour and beliefs in the developing world offers promising lines of enquiry for medical geography. Importantly, such a perspective forces us to think differently about the relationships between socio-cultural change and health care practices, and encourages us to question the assumption that local health care practices in such societies represent a transitional phase as they move towards modern western regimes of health behaviour and beliefs.

\section{ACKNOWLEDGEMENTS}

We are indebted to many people for assistance and hospitality during fieldwork. We are particularly grateful to villagers from Miko who generously gave their time and assistance. We thank the referees for their helpful comments on the paper, and Mike Mickler for redrawing Figure 1. Fieldwork in 1996 was partly funded by an Australian Research Council Small Grant from Curtin University of Technology.

\section{NOTES}

1. Mobile $\mathrm{MCH}$ patrols exist nation-wide and provide immunisation, antenatal screening, growth monitoring, illness treatment, family planning and health education.

2. This astonishingly high rate of out-migration may be symptomatic of increasing resource pressures in the Wosera (Curry and Koczberski, in press).

3. Individuals mentioned in this study have been given pseudonyms for reasons of confidentiality.

\section{REFERENCES}

Allen, B.J., 1976: Information flow and innovation diffusion in the East Sepik District, Papua New Guinea. Unpublished Ph.D. thesis, The Australian National University, Canberra.

Anderson, K.J. and Gale, G.F. (eds), 1992: Inventing Places. Studies in Cultural Geography. Longman Cheshire, Melbourne.

Bailey, K.V., 1963: Nutritional status of East New Guinean populations. Tropical Geographical Medicine 15, 389402.

Boyd, D.J., 1985: The commercialisation of ritual in the Eastern Highlands of Papua New Guinea. Man 20, 325340 .

Brookfield, H.C., 1973: Explaining or understanding? The study of adaption and change. In Brookfield, H.C. (ed.) The Pacific in Transition. Geographical Perspectives on Adaption and Change. Edward Arnold, London, 3-23.

Brown, M., 1995: Ironies of distance: an ongoing critique of the geographies of AIDS. Environment and Planning D: Society and Space 13, 159-183.

Carrier, J. and Carrier, A., 1989: Wage, Trade, and Exchange in Melanesia. A Manus Society in Modern State. University of California Press, Berkeley.

Clifford, J., 1997: Routes. Travel and Translation in the Late Twentieth Century. Harvard University Press, Massachusetts.

Cogill, B. and Clarke, L.J., 1984: The assessment and classification of the nutritional status of children under five years old. In Allen, B.J. (ed.) Agricultural and Nutritional Studies on the Nembi Plateau. Department of Geography Occasional Paper 4, The University of Papua 
New Guinea and the Southern Highlands Rural Development Project, Port Moresby, 78-88.

Connell, J., 1997: Health in Papua New Guinea: a decline in development. Australian Geographical Studies 35, 271293.

Conton, L.C., 1985: Social economic and ecological parameters of infant feeding in Usino, Papua New Guinea. Ecology of Food and Nutrition 16, 39-54.

Crittenden, R., 1982: Sustenance, seasonality and social cycles on the Nembi Plateau, Papua New Guinea. Unpublished Ph.D. thesis, The Australian National University, Canberra.

Crush, J. (ed), 1995: Power of Development. Routledge, London.

Curry, G.N., 1992: Kin and Kina: a study of emerging inequalities in a rural lowland society in Papua New Guinea. Unpublished Ph.D. thesis, The University of New England, Armidale.

Curry, G.N., 1997: Warfare, social organisation and resource access amongst the Wosera Abelam of Papua New Guinea. Oceania, 67, 194-217.

Curry, G.N., 1999: Markets, social embeddedness and precapitalist societies: the case of village tradestores in Papua New Guinea. Geoforum 30, 285-298.

Curry, G.N. and Koczberski, G., 1998: Migration and circulation as a way of life for the Wosera Abelam of Papua New Guinea. Asia Pacific Viewpoint, 39(1), 29-52.

Curry, G.N. and Koczberski, G., in press: The risks and uncertainties of migration: an exploration of recent trends amongst the Wosera Abelam of Papua New Guinea. Oceania.

Edwards, K., 1989: The diagnosis and management of childhood undernutrition. Papua New Guinea Medical Journal 32, 143-150.

Escobar, A., 1995: Encountering Development: the Making and Unmaking of the Third World. Princeton University Press, New Jersey.

Eyles, J. and Donovan, J., 1986: Making sense of sickness and care: an ethnography of health in a West Midlands town. Transactions of the Institute of British Geographers N.S. 11, 415-427.

Forge, A., 1971: Marriage and exchange in the Sepik: comments on Francis Korn's analysis of Iatmul society. ASA Monograph II, 133-144.

Forge, A., 1990: The power of culture or vice-versa. In Lutkehaus, N., Kaufman, C., Mitchell, W.E., Newton, D., Osmundsen, L. and Schuster, M. (eds) Sepik Heritage: Tradition and Change in Papua New Guinea. Carolina Academic Press, Durham, 160-170.

Frankel, S., 1986: The Huli Response to Illness. Cambridge University Press, Cambridge.

Frankel, S. and Lewis, G., 1989: Patterns of continuity and change. In Frankel, S. and Lewis, G. (eds) A Continuing Trial of Treatment: Medical Pluralism in Papua New Guinea. Kluwer Academic Publishers, Dordrecht, Holland, 1-33.

Garner, P., 1989: The epidemiology of maternal and neonatal health in Papua New Guinea. Unpublished M.D. thesis, The University of London, London.

Gesler, W., 1991: The Cultural Geography of Health Care. University of Pittsburgh Press, Pittsburgh.

Gesler, W., 1992: Therapeutic landscapes: medical issues in light of the new cultural geography. Social Science and Medicine 34, 735-746.

Gillett, J., 1990: The Health of Women in Papua New Guinea. Papua New Guinea Institute of Medical Research, Madang.

Good, C., 1987: Ethnomedical Systems in Africa: Patterns of Traditional Medicine in Rural and Urban Kenya. Guilford Press, New York.

Gregory, C.A., 1982: Gifts and Commodities. Academic Press, London.

Hamnett, M. and Connell, J., 1981: Diagnosis and cure: the resort to traditional and modern medical practitioners in the North Solomons, Papua New Guinea. Social Science and Medicine 15B, 489-498.

Heywood, P., Allen, B., Fandim, T., Garner, P., Hide, R., Joughin, J., Junembarry, J., Mathie, A., Numbuk, S., Ross, J. and Yaman, C., 1986: A Rapid Rural Appraisal of Agriculture, Nutrition and Health in the Wosera subdistrict, East Sepik Province. Papua New Guinea Institute of Medical Research, Madang.

Heywood, P., Singleton, N. and Ross, J., 1988: Nutritional status of young children - the 1982/83 National Nutritional Survey. Papua New Guinea Medical Journal 31, 91-102.

Howlett, D.R., 1973: Terminal development: from tribalism to peasantry. In Brookfield, H.C. (ed.) The Pacific in Transition. Geographical Perspectives on Adaption and Change. Edward Arnold, London, 249-273.

Jackson, J.C. and Jackson-Carroll, L., 1994: The social significance of routine health behavior in Tamang daily life. Social Science and Medicine 38, 999-1010.

Jenkins, C., 1992: Medical anthropology in Papua New Guinea: a challenge. In Attenborough, R. and Alpers, M. (eds) Human Biology in Papua New Guinea. The Small Cosmos. Oxford University Press, Oxford.

Jenkins, C., Orr-Ewing, O.L. and Heywood, P., 1984: Cultural aspects of early childhood growth and nutrition among the Amele of lowland Papua New Guinea. Ecology of Food and Nutrition 14, 261-275.

Kaberry, P.M., 1941: The Abelam tribe, Sepik District, New Guinea: a preliminary report. Oceania 12, 79-95.

Kearns, R. and Joseph, A., 1993: Space in its place: developing the link in medical geography. Social Science and Medicine 37, 711-717.

Kirby, J.P., 1997: White, red and black: colour classification and illness management in Northern Ghana. Social Science and Medicine 44, 215-230.

Koczberski, G., 1989: Child nurturing practices in the Wosera area of the East Sepik Province, Papua New Guinea: implications for the nutritional status of young children up to three years of age. Unpublished B.A. (Honours) thesis, Department of Geography and 
Planning, The University of New England, Armidale.

Landrine, H. and Klonoff, E., 1994: Cultural diversity in causal attributions for illness: the role of the supernatural. Journal of Behavioural Medicine 17, 181-193.

Lea, D.A.M., 1964: Abelam land and sustenance. Unpublished Ph.D. thesis, The Australian National University, Canberra.

Lea, D.A.M., Joel, N. and Curry G.N., 1988: A Maprik journey: backwards or forwards in time? Cash cropping among the Abelam. In Hirst, J., Overton, J., Allen, B. and Bryon, Y. (eds) Small-scale Agriculture. Commonwealth Geographical Bureau and Department of Human Geography, Research School of Pacific Studies, The Australian National University, Canberra, 23-31.

Lepowsky, M., 1990: Sorcery and penicillin: treating illness on a Papua New Guinea Island. Social Science and Medicine 10, 1049-1063.

Lewis, G., 1975: Knowledge of Illness in a Sepik Society: a Study of the Gnau, New Guinea. Athlone, London.

Lipuma, E., 1989: Modernity and medicine among the Maring. In Frankel, S. and Lewis, G. (eds) A Continuing Trial of Treatment: Medical Pluralism in Papua New Guinea. Kluwer, Dordrecht, 295-310.

Malcolm, L.A., 1970: Growth, malnutrition and mortality of the infant and toddler in the Asai Valley of the New Guinea Highlands. American Journal of Clinical Nutrition 23, 1000-1095.

Nabudere, D., 1997: Beyond modernization and development, or why the poor reject development. Geografiska Annaler 79B, 203-215.

Nederveen Pieterse, J., 1994: Globalisation as hybridisation. International Sociology 9, 161-184.

Obrist van Eeuwijk, B., 1992: Small but Strong: Cultural Context of (Mal-)Nutrition among the Northern Kwanga (East Sepik Province, Papua New Guinea). Wepf, Basel.

Peters, W., 1960: Studies on the epidemiology of malaria in New Guinea. Transactions of the Royal Society of Tropical Medicine and Hygiene 54, 242-260.

Philip, L., 1998: Combining quantitative and qualitative approaches to social research in human geography — an impossible mixture? Environment and Planning A 30, 261-276.

Phillips, D.R., 1990: Health and Health Care in the Third World. Longman, Harlow.

Pollock, D., 1996: Personhood and illness among the Kulina. Medical Anthropology Quarterly 10, 319-341.

Roberts, B.R., 1978: Cities of Peasants: the Political Economy of Urbanization in the Third World. Edward Arnold, London.

Roscoe, P., 1989: Medical pluralism among the Yangoru Boiken. In Frankel, S. and Lewis, G. (eds) A Continuing Trial of Treatment: Medical Pluralism in Papua New Guinea. Kluwer, Dordrecht, 199-215.

Ross, J., 1984: Subsistence under stress: nutritional implications in the Wosera, Papua New Guinea. Unpublished M.Sc. thesis, University of Guelph, Guelph.

Schofield, F.D., 1963: Health and nutritional status of the people of the Wosera. Unpublished report to the Public Health Department, Port Moresby.

Schwartz, L., 1969: The hierarchy of resort in curative practices: the Admiralty Islands, Melanesia. Journal of Health and Social Behavior 10, 201-209.

Shack, K.W., Griveth, L. and Dewey, K., 1990: Cash cropping, subsistence agriculture and nutritional status among mothers and children in lowland Papua New Guinea. Social Science and Medicine 31, 61-68.

Simon, D., 1997: Development reconsidered: new directions in development thinking. Geografiska Annaler 79B, 183201.

Simon, D., 1998: Rethinking (post)modernism, post colonialism, and post traditionalism: South-North perspectives. Environment and Planning D: Society and Space 16, 219-245.

Thomas, N., 1991: Entangled Objects: Exchange, Material Culture, and Colonialism in the Pacific. Harvard University Press, Cambridge.

Tyson, D., 1987: An ecological analysis of child malnutrition in an Abelam community, Papua New Guinea. Unpublished Ph.D. thesis, The Australian National University, Canberra. 